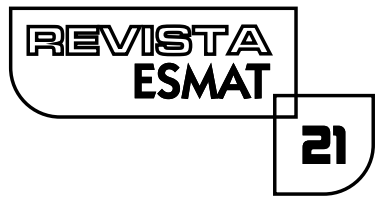

\title{
OS DIREITOS HUMANOS E O DIREITO À PROTEÇÃO INTEGRAL AO ADOLESCENTE EM CONFLITO COM A LEI
}

HUMAN RIGHTS AND THE RIGHT TO INTEGRAL PROTECTION OF ADOLESCENTS IN CONFLICT WITH LAW

Paulo Sérgio Gomes Soares

Doutor em Educação (UFSCar/20 I2). Mestre em Filosofia (UNESP/2004). Graduado em Filosofia (UNESP/1 997) Professor no Programa de Pós-Graduação Mestrado Profissional em Prestação Jurisdicional e Direitos Humanos (UFT/ESMAT) e no Mestrado Profissional em Filosofia (PROF-FILO/UFT). Bolsista FAPTO. E-mail: psoares@uft.edu.br

Hélvia Túlia Sandes Pedreira

Mestra em Prestação Jurisdicional e Direitos Humanos (UFT/ESMAT/20 I 9). Especialista em Direito e Processo do Trabalho (UFG/I 997). Graduada em Direito (UFG/I 993). Atua como juíza de direito no Tribunal de Justiça do Estado do Tocantins, Comarca de Porto Nacional. E-mail: helviatulia@bol.com.br

\section{RESUMO}

Tendo em vista os Direitos Humanos, para além de uma análise da responsabilização do adolescente em conflito com a lei, a partir dos instrumentos normativos e do marco teórico do Direito Penal Juvenil, a proposta deste artigo é refletir sobre a atuação do legislador guiada pelo princípio da proporcionalidade adequada e limitada à proteção aos bens jurídicos fundamentais, bem como da subsidiariedade para a intervenção socioeducativa mínima ao adolescente em conflito com a lei. A atuação repressiva e punitiva desvinculada da medida socioeducativa mínima impõe um caráter sancionatório e pedagógico que não coaduna com o agir proporcional do legislador por desrespeito ao direito à proteção integral, considerando os tratados internacionais dos quais o Brasil é signatário. $\bigcirc$ artigo apresenta uma pesquisa teórica de cunho fenomenológico que possibilita uma reflexão crítica acerca da atuação do legislador em consonância com os tratados internacionais e com o Estatuto da Criança e do Adolescente aos paradigmas do estado democrático de direito diante da condição do adolescente como sujeito de direito com prioridade absoluta.

PALAVRAS-CHAVE: Direitos Humanos. Direito Penal Juvenil. Estatuto da Criança e do Adolescente. Princípio da Proporcionalidade. Princípio da Subsidiariedade. 


\section{ABSTRACT}

With views on human rights, in addition to an analysis of the responsibility of the adolescent in conflict with the law, from the normative instruments and the theoretical framework of Juvenile Criminal Law, the proposal of this article is to reflect on the action of the legislator guided by the principle of adequate proportionality and limited to the protection of fundamental legal rights, as well as of the subsidiarity for the minimum socio-educational intervention to the adolescent in conflict with the law. The repressive and punitive action unrelated to the minimum socio-educational measure imposes a sanctioning and pedagogical character that does not fit with the proportional action of the legislator for disrespect to the right to integral protection, considering the international treaties to which Brazil is a signatory. The article presents a theoretical research of a phenomenological nature that allows a critical reflection on the work of the legislator in consonance with the international treaties and the Statute of the Child and the Adolescent to the paradigms of the democratic state of right before the condition of the adolescent like subject of the right with absolute priority.

KEYWORDS: Human rights. Criminal Law. Juvenile Criminal. Statue of the Child and the Adolescent. Principle of Proportionality. Principle of Subsidiarity.

\section{INTRODUÇÃO}

Brasil é signatário de dois dos principais tratados internacionais que visam exclusivamente à proteção da criança e do adolescente: a Convenção sobre os Direitos da Criança e as Regras Mínimas das Nações Unidas para a Administração da Justiça da Infância e da Juventude, adotadas pela Resolução n 40/33, de 29 de novembro de 1985, na Assembleia Geral da Organização das Nações Unidas, conhecida como Regras de Beijing, e os Princípios das Nações Unidas para a Prevenção da Delinquência Juvenil, Documento das Nações Unidas n A/CONF. 157/24 (Parte I), 1990, conhecido como Diretrizes de Riad.

As Regras de Beijing e as Diretrizes de Riad reconhecem o comportamento desviante como parte do processo de amadurecimento e preconizam a preservação do "interesse geral do jovem", a partir de um critério de justiça e equidade, com a adoção de medidas capazes de reduzirem a necessidade de intervenção estatal à criminalização e à penalização de condutas. Portanto, qualquer intervenção que não esteja em conformidade com o previsto nesses tratados internacionais constitui violência das agências estatais contra a criança e o adolescente. 
Diante desse quadro, a ordem constitucional brasileira reconhece os direitos fundamentais e lhes confere caráter de objetividade. A Lei n 8.069, de I 3 de julho de 1990, que dispõe sobre o Estatuto da Criança e do Adolescente (ECA), reafirma esse caráter de objetividade e está de acordo com os tratados internacionais. Neste Estatuto está prevista a imputabilidade dos menores de dezoito anos (art. 104) e considera como ato infracional a conduta do adolescente descrita como crime ou contravenção penal (art. 103). Então, verificada a prática do ato infracional, a autoridade judiciária pode aplicar medidas socioeducativas ao adolescente (art. I I2), e para as crianças autoras de atos infracionais há a previsão de aplicação de medidas protetivas (art. 105). Delineiam-se, portanto, as diferenças de tratamento destinadas à criança e ao adolescente.

Neste artigo se privilegiaram a análise do tratamento dispensado ao ato infracional cometido por adolescente e as medidas socioeducativas como garantias legais dos direitos do adolescente. Mesmo sendo inserido no sistema de justiça em razão da sua própria conduta por ato infracional tipificado como crime ou contravenção, o adolescente possui prioridade absoluta.

A proteção dos direitos fundantes numa perspectiva objetiva parte do pressuposto de que não é apenas o Estado que se obriga a observar os direitos individuais em face do poder público, mas também deve fixar mecanismos que assegurem a observância desses direitos por terceiros.

A atuação do legislador, nesse sentido, ao definir a proteção aos bens jurídicos fundamentais, deve ser adequada e limitada - adequação e limite guiados pelo princípio da proporcionalidade. Assim, o agir proporcional do legislador pressupõe legitimidade dos meios e fins buscados, bem assim que os meios sejam adequados e necessários aos fins.

Transportar os parâmetros que guiam o agir proporcional do legislador para o âmbito da responsabilização do adolescente por condutas caracterizadas como atos infracionais - crimes e contravenções - requer a análise em dois momentos distintos. Primeiro, verificar se o amplo espectro dos atos infracionais - crimes e contravenções - pune, porém conferindo o meio legítimo e adequado de proteção integral ao adolescente em razão da sua conduta que passa a ser enquadrada como desviante; segundo, se as medidas socioeducativas, como mecanismo retributivo e ressocializador, são meios adequados e necessários para responsabilizar e ressocializar o adolescente em conflito com a lei.

Os limites da intervenção estatal na responsabilização e ressocialização do adolescente devem ser estabelecidos a partir de uma intervenção estatal mínima, excepcional e subsidiária. Qualquer forma de violência das agências estatais deve ser vista como desrespeito aos Direitos Humanos. Constatação que insta a identificação de mecanismos minimizadores da intervenção socioeducativa e possa tratar o adolescente de forma equitativa e humanitária, reconhecendo a condição 
de sujeito ao adolescente com papel social ativo e colaborante, e não objeto de medidas de socialização e controle.

Colocar no adolescente a pecha de infrator por condutas as mais variadas sem conteúdo material violador de bens jurídicos fundamentais e estabelecer uma responsabilização desvinculada do caráter pedagógico não coadunam com a sua condição de sujeito de direito e prioridade absoluta. A análise dos instrumentos normativos que regulam a intervenção estatal acerca do adolescente em conflito com a lei evidencia a ausência de instrumentos normativos que busquem minimizar a intervenção socioeducativa que, muitas vezes, pode ser mais gravosa que a imposta ao inimputável.

O objetivo deste artigo é refletir sobre a atuação do legislador guiada pelo princípio da proporcionalidade adequada e limitada à proteção aos bens jurídicos fundamentais, bem como da subsidiariedade para a intervenção punitiva como caminho para a efetivação de uma intervenção socioeducativa mínima ao adolescente em conflito com a lei.

Tendo em vista os Direitos Humanos, é fundamental ir além de uma análise da responsabilização do adolescente em conflito com a lei, a partir dos instrumentos normativos e do marco teórico do Direito Penal Juvenil, pois a atuação repressiva desvinculada da medida socioeducativa mínima impõe um caráter sancionatório e pedagógico que não coaduna com o agir proporcional do legislador, sobretudo por desrespeitar o direito à proteção integral, considerando os tratados internacionais dos quais o Brasil é signatário. Trata-se de uma pesquisa teórica de cunho fenomenológico que possibilita uma reflexão crítica acerca da necessidade de compatibilizar o Estatuto da Criança e do Adolescente às premissas traçadas pelos tratados internacionais, aos paradigmas do estado democrático de direito e à condição do adolescente como sujeito de direito com prioridade absoluta.

A legitimidade da intervenção estatal na esfera da responsabilização do adolescente deve se pautar em instrumentos normativos na doutrina, valendo-se da analogia e do método dedutivo com o objetivo de demonstrar que o marco teórico do Direito Penal Juvenil confere viabilidade à aplicação das teorias do Direito Penal Mínimo e da subsidiariedade da intervenção punitiva como caminhos a serem trilhados na efetivação de uma intervenção socioeducativa mínima.

\section{PARÂMETROS NORMATIVOS DA RESPONSABILIZAÇÃO PE- NAL JUVENIL}

A Constituição Federal, de 1988, trouxe ampla modificação dos marcos legais e conceituais da infância e da adolescência no Brasil. A teoria da situação irregular, base do Código de Menores, foi substituída pela Teoria da Proteção Integral, reconhecendo direitos fundamentais à criança e ao adolescente, além de lhes conferir 
prioridade absoluta e a condição de credores de direitos que devem ser assegurados pela família I, pela sociedade e pelo Estado (art. 227 da Constituição Federal).

A teoria da situação irregular, no art. $2^{\circ}$ do Código de Menores, Lei n 6.697, de 10 de outubro de 1979, diz o seguinte: Art. $2^{\circ}$ Para os efeitos deste Código, considera-se em situação irregular o menor: I - privado de condições essenciais à sua subsistência, saúde e instrução obrigatória, ainda que eventualmente, em razão de: a) falta, ação ou omissão dos pais ou responsável; b) manifesta impossibilidade dos pais ou responsável para provê-las; II - vítima de maus tratos ou castigos imoderados impostos pelos pais ou responsável; III - em perigo moral, devido a: a) encontrar-se, de modo habitual, em ambiente contrário aos bons costumes; b) exploração em atividade contrária aos bons costumes; IV - privado de representação ou assistência legal, pela falta eventual dos pais ou responsável; $\vee$ - com desvio de conduta, em virtude de grave inadaptação familiar ou comunitária; VI - autor de infração penal.

Diferentemente, a arrojada teoria da proteção integral tem suas bases firmadas no art. 227 da Constituição Federal, que estabelece ser "dever da família, da sociedade e do Estado assegurar à criança, ao adolescente e ao jovem, com absoluta prioridade, o direito à vida, à saúde, à alimentação, à educação, ao lazer, à profissionalização, à cultura, à dignidade, ao respeito, à liberdade e à convivência familiar e comunitária, além de colocá-los a salvo de toda forma de negligência, discriminação, exploração, violência, crueldade e opressão (art. 227 da Constituição Federal, de 1988, com a redação dada Pela Emenda Constitucional n. 65, de 2010$)$. A teoria da proteção integral é firmada no tripé do reconhecimento da criança e do adolescente como sujeitos de direitos; prioridade absoluta na efetivação de direitos e respeito à condição peculiar de pessoa em desenvolvimento.

Hoje, sabe-se que o espectro protetor do adolescente em conflito com a lei estabelece como penalmente inimputáveis os menores de dezoito anos (art. 228 da Constituição Federal), sujeitando-o às normas da legislação especial.

A Convenção Internacional sobre os Direitos da Criança, Decreto n 99.710, de 1990, preconiza a proteção integral à criança e ao adolescente partindo do reconhecimento de sua autonomia, não deixando de considerar as limitações de sua capacidade de exercício dos direitos e da sua liberdade como sujeitos em desenvolvimento. Diante disso, confere garantias de respeito à dignidade e valor às crianças e aos adolescentes em conflito com a lei, fortalecendo o respeito aos Direitos Humanos e pelas liberdades fundamentais, impondo aos Estados-membros a adoção de "medidas para tratar dessas crianças sem recorrer a procedimentos judiciais", respeitando os Direitos Humanos e as garantias legais.

I A família é a base fundante da sociedade (art. 226 da Constituição Federal). 
A convenção alia o conceito progressivo de liberdade de expressão e opinião, como também aos de responsabilidade, não só social, mas também penal, considerando o grau de maturidade (SARAIVA, 2004).

No âmbito da criança e do adolescente em conflito com a lei, as Regras de Beijing preconizam, nos seus princípios gerais, a necessidade de serem adotadas medidas capazes de mobilizar a família, voluntários, grupos comunitários, com a finalidade de promover o "bem-estar do menor e reduzir a necessidade de intervenção da lei e tratar de forma eficaz, equitativa e humanitária o jovem em conflito com a lei".

As Diretrizes de Riad, por sua vez, reconhecem a importância de políticas e medidas de prevenção à delinquência infanto-juvenil para evitar a criminalização e a penalização de condutas que não causem grandes prejuízos ao desenvolvimento, além de limitar a intervenção Estatal à preservação do "interesse geral do jovem", a partir de um critério de justiça e equidade. Adverte, ainda, para a necessidade de se reconhecer que o comportamento desviante do adolescente, com frequência, faz parte do processo de amadurecimento.

Considerando a condição especial do adolescente, de pessoa em desenvolvimento, as Diretrizes de Riad também preconizam a adoção de programas e serviços comunitários na prevenção da delinquência juvenil, e conferem o caráter de excepcionalidade à intervenção dos organismos formais de controle social.

A conjunção das normativas internacionais reconhece o comportamento desviante do adolescente, ao mesmo tempo em que limita a intervenção estatal a situações que importem em risco pessoal ou a terceiro, privilegiando soluções que afastem a penalização e a criminalização.

Nessa esteira, o Estatuto da Criança e do Adolescente, reafirmando a inimputabilidade dos menores de dezoito anos (art. I04, ECA), considera como ato infracional a conduta do adolescente descrita como crime ou contravenção penal (art. 103, ECA). Verificada a prática do ato infracional, o adolescente está sujeito à aplicação, pela autoridade judiciária, de medidas socioeducativas (art. II2, ECA). Às crianças autoras de ato infracional, prevê-se a adoção de medidas de proteção (art. 105, ECA).

No caso dos adolescentes, as medidas socioeducativas são várias. Podem importar numa admoestação - advertência (art. I I2, inciso I, ECA); na reparação do dano (art. II2, inciso, II, ECA); em restrições de direitos como as medidas de prestação de serviços à comunidade e liberdade assistida (art. I I2, incisos III e IV, ECA), ou até mesmo em privação da liberdade, sob as formas de semiliberdade (art. I I 2, inciso V, ECA) ou internação (art. I I2, inciso VI, ECA), medidas socioeducativas, estas possíveis de serem aplicadas quando o ato infracional for praticado com violência ou grave ameaça a pessoa (art. 122, ECA).

Embora o Estatuto da Criança e do Adolescente tenha consolidado um novo marco teórico a partir do abandono da teoria da situação irregular e adoção da 
teoria da proteção integral, uma análise das suas disposições, no tocante ao adolescente em conflito com a lei, evidencia traços da doutrina menorista ao conferir amplo espectro aos atos infracionais, abrangendo tanto o crime como as contravenções penais.

$\bigcirc$ Estatuto da Criança e do Adolescente reconhece essas condutas como desviantes, sujeitando os adolescentes à socioeducação, devendo assegurar, imperativamente, o devido processo legal para a imposição da medida socioeducativa ao adolescente infrator (art. I I0, ECA).

A responsabilização do adolescente de forma tão ampla diante de um comportamento desviante, considerando a sua situação peculiar de pessoa em desenvolvimento e em processo de amadurecimento, distancia-se das diretrizes traçadas na normativa internacional, em especial as Diretrizes de Riad, ao preconizar uma responsabilização do jovem quando sua conduta ocasionar riscos pessoais ou a terceiros, buscando soluções que preservem a convivência familiar e comunitária, afastando o estigma da penalização e da criminalização.

A ausência de um arcabouço principiológico próprio quanto à "responsabilização jurídica dos menores de dezoito anos não obstaculiza a incidência da estrutura de garantias previstas aos imputáveis autores de delitos", que, ao irradiar seu espectro aos adolescentes em conflito com a lei, amplia o sistema de garantias, limita qualquer forma de intervenção estatal de caráter punitivo-sancionador (CARVALHO; WEIGERT, 20I2, p. 3-4) e afasta o caráter tutelar que, imbuído da ideia de proteger e beneficiar o adolescente, acaba por legitimar violações de direitos.

$\bigcirc$ ordenamento constitucional, quando confere aos direitos fundamentais uma "feição objetiva" e "legitima a ideia de que o Estado se obriga não apenas a observar os direitos de qualquer indivíduo em face do Poder Público, como também a garantir direitos fundamentais contra agressão de terceiros" (MENDES, RE 635659/SP, p. 4), exige uma adequação da atuação do legislador ao definir a "proteção a bens jurídicos fundamentais" e limita sua atuação ao princípio da proporcionalidade que "pressupõe não só a legitimidade dos meios utilizados e dos fins perseguidos, como também, igualmente, a adequação dos meios para a consecução dos objetivos pretendidos e a necessidade de sua utilização" (MENDES, RE 635659/SP, p. 6).

$\bigcirc$ agir proporcional do legislador, no âmbito da responsabilização do adolescente por condutas caracterizadas como atos infracionais - crimes e contravenções -, requer a verificação se o amplo espectro dos atos infracionais confere proteção a bens jurídicos fundamentais e proteção integral ao adolescente em razão da sua conduta desviante; bem como se as medidas socioeducativas, como mecanismo retributivo e ressocializador, são meios adequados e necessários para responsabilizar e ressocializar o adolescente em conflito com a lei. 


\section{DESCRIMINALIZAÇÃO E INTERVENÇÃO SOCIOEDUCATIVA MÍNIMA E SUBSIDIÁRIA}

A análise da intervenção estatal na esfera da responsabilização do adolescente pela prática de atos infracionais, como já apontado, é perpassada por um juízo de proporcionalidade, a ser exercido em dois momentos. No primeiro momento, deve-se analisar se a abrangência das condutas reconhecidas como desviantes crimes e contravenções - estabelece proteção a bens jurídicos fundamentais e se a sanção é necessária diante da subsidiariedade da intervenção punitiva e da proteção integral ao adolescente.

Num segundo momento, a análise deve se voltar à forma de responsabilização do adolescente pela imposição de medidas socioeducativas, a fim de se aferir se elas são meios legítimos para se atingirem os fins retributivo, educativo e ressocializador; e também adequados e necessários à responsabilização e à ressocialização do adolescente em conflito com a lei.

As balizas para análise são preconizadas nas Diretrizes de Riad quando firma uma política de prevenção, a excepcionalidade da intervenção dos organismos formais de controle social, e opta pela adoção de soluções que preservem a convivência familiar e comunitária, de forma a não estigmatizar e penalizar o adolescente.

reconhecimento da inimputabilidade penal dos menores de dezoito anos (art.228 da Constituição Federal, de 1988) afasta a imposição de pena, mas não a responsabilização e a imposição de medidas socioeducativas ao adolescente diante da prática de ato infracional. Embora a estruturação dos atos infracionais estabeleça uma correlação entre ato infracional e condutas tipificadas como crimes e contravenções penais, não pondera se todas essas condutas, quando praticadas por adolescente, reclamam uma necessária intervenção estatal, tampouco levam em conta a situação peculiar de pessoa em desenvolvimento, desconhecendo ser o comportamento desviante, não raro, integrante do processo de amadurecimento.

É certo que a ordem constitucional estabelece proteção aos direitos fundamentais com um viés objetivo e traz um "mandado de criminalização dirigido ao legislador", considerando "bens e valores objeto de proteção", garantindo direitos fundamentais em face da atuação estatal e de terceiros (MENDES, RE 635659/ SP, p. 4).

Nesse sentido, reafirma-se, no atual contexto, a origem do discurso criminológico no Brasil, permeada pela ideia de controle a ser realizado sobre os loucos, criminosos, crianças e adolescentes. No caso de adolescentes em conflito com a lei, importante parte da doutrina não reconhece nas medidas socioeducativas caráter punitivo/sancionador. Ao contrário, entende ser a forma aberta de escolha de mecanismo que possibilita ao julgador eleger, a partir da teoria da proteção integral, a medida socioeducativa mais adequada a interferir no processo de de- 
senvolvimento do adolescente, "objetivando melhor compreensão da realidade e efetiva integração social" (MAIOR, 2004, p. 378).

A normatização das condutas desviantes dos adolescentes e a sua responsabilização não podem ser permeadas de subjetividade e discricionariedade, tampouco na ideia utópica de serem as medidas socioeducativas capazes de resgatar a condição de cidadania e protagonista do adolescente; e, respeitando a sua condição de sujeito de direito, reinseri-lo socialmente e prepará-lo para uma harmoniosa convivência coletiva. Ao contrário, reforça o argumento criminológico de manutenção da ordem e da disciplina, bem como o caráter assistencialista e tutelar ainda pulsante que afasta o adolescente da condição de sujeito de direitos.

Necessário reconhecer que as medidas socioeducativas, que podem ser aplicadas aos adolescentes têm um viés sancionador por importar em limitações a direitos e liberdades fundamentais. Para que o legislador não incorra nessas limitações, a adoção da doutrina do direito penal juvenil é adequada para densificar garantias constitucionais e processuais ao adolescente em conflito com a lei, ao possibilitar a irradiação de teorias, valores e garantias processuais asseguradas aos imputáveis e afastar o caráter tutelar da responsabilização. Encontra também justificativa normativa no Estatuto da Criança e do Adolescente, quando possibilita a aplicação subsidiária (art. I 52, ECA) do Código de Processo Penal às normas do Estatuto ampliando as regras garantidoras do devido processo legal e limitando a atuação sancionadora estatal.

No âmbito das políticas criminais no estado democrático de direito, aqui adotada diante da equiparação do ato infracional a crimes e contravenções e do marco teórico do Direito Penal Juvenil, a criminalização deve adotar uma perspectiva material e somente pode atingir condutas que visem proteger "bens jurídicos imprescindiveis à coexistência pacífica dos homens e que não podem ser eficazmente protegidos de forma menos gravosa" (PRADO, 2006, p. I38). O conceito material de crime possui uma noção pré-legal, conforme segue:

por conceito material de crime vem-se entendendo, de modo cada vez mais difundido, uma noção pré-legal, com finalidade político-criminais, daquilo que deve ser punível dentro de um estado social de direito. Com base nele se 'pergunta o que pode ser proibido na nossa atual ordem jurídica e social' [...]. Costuma-se apontar como seu conteúdo uma lesão a bem jurídico, ou um comportamento socialmente danoso, que não possa ser evitado com nenhum outro meio da ordem jurídica, tornando-se necessário o recurso à ultima ratio, que é o direito penal. (ROXIN, 2008, p. 12).

Depreende-se do excerto que a noção pré-legal de crime pode produzir a eliminação do crime, isto é, pode descriminalizar as condutas tipificadas como não violadoras da paz social e da ordem jurídica. No estado democrático de direito 
não se deveriam punir comportamentos que causem a autolesão ou a "autocolocação em perigo". Obsta enfatizar que tais condutas não pertencem ao campo do Direito Penal. Ao Direito Penal "incumbe impedir danos a terceiros e garantir as condições de coexistência social" (ROXIN, 2008, p. 12).

A concepção de condutas sujeitas à penalização, a partir de um caráter material vinculado à ideia "pré-legal" do que deve ser reconhecido como comportamentos puníveis "na atual ordem jurídica e social", desvincula a conduta desviante do sujeito, ao mesmo tempo passa a considerar o crime como comportamento definido objetivamente pelo direito.

O resguardo a direitos fundamentais e à liberdade individual impõe limitações ao poder estatal de punir. Limitação firmada a partir da finalidade do direito penal no âmbito do ordenamento estatal. Roxin (2008, p. 32) reconhece ser consenso na cultura ocidental e em outras partes do mundo a finalidade de o Direito Penal "garantir os pressupostos de uma convivência pacífica, livre e igualitária entre os homens, à medida que isso seja possível por meio de outras medidas de controle sociopolíticas menos gravosas".

Como limitadora da liberdade individual não pode a lei penal estabelecer proibições desnecessárias à convivência livre e pacífica (ROXIN, 2008, p. 32-33) e só encontrará justificação quando, por outros meios, não for possível atingir suas finalidades.

Da finalidade da norma penal de "proteção subsidiária de bens jurídicos" decorrem, em grande parte, os seus limites. Assim, é objetivo do direito penal impedir danos sociais, que não podem ser evitados com outros meios, menos gravosos. A proteção de bens jurídicos, no âmbito da penalização das condutas, significa impedir danos sociais (ROXIN, 2008, p. 35). Sem danos sociais não pode haver limitações à liberdade individual.

A concepção do crime sob o viés material importa em descriminalizar condutas que não acarretem violação da paz social e no reconhecimento do caráter subsidiário do Direito Penal. Como ultimaratio, por limitar liberdades individuais, a cominação de penas somente encontra justificação quando "a eliminação do distúrbio social não puder ser obtida através de meios extrapenais menos gravosos" (ROXIN, 2008, p. 13).

Segundo Cavalcanti (2005, p. 302), a intervenção mínima sobreleva "o caráter fragmentário do Direito Penal" ao proteger "tão somente valores imprescindíveis para a sociedade", limita a atuação do legislador por não ser possível "utilizar o direito penal como instrumento de tutela de todos os bens jurídicos".

O Estatuto da Criança e do Adolescente (1990), em compasso com a Convenção Internacional sobre os Direitos da Criança, ao superar o paradigma da incapacidade, passou a reconhecer o adolescente como sujeito de direito, mas adotou a responsabilização em caso de ato infracional, impondo-lhe a aplicação de medidas socioeducativa. No entanto, sem considerar se a conduta do adolescen- 
te, reconhecida como desviante, necessita de controle como forma de manutenção da paz social, tampouco se os comportamentos são "socialmente lesivos" no momento de estabelecer a responsabilização, com a aplicação de sanções.

Nesse contexto, o adolescente em conflito com a lei tem o reconhecimento da conduta sujeita a sanções "penais" e à responsabilização, mas deveria agregar o aspecto do sujeito na sua condição peculiar de pessoa em desenvolvimento que merece especial proteção, sem desmerecer o caráter tutelar. O subjetivismo discricional deveria ser retirado e inserida a observância de regras objetivas de garantias processais e do devido processo legal.

No âmbito do ato infracional - crimes e contravenções -, o debate feito por Roxin reconhece o caráter material das condutas desviantes e a subsidiariedade da intervenção punitiva, apesar do caráter material, que é perfeitamente adequado para afastar da normatização como ato infracional condutas que não protejam bens jurídicos fundamentais e não objetivam manter a paz social; como também para justificar a responsabilização do adolescente como ultimaratio, ou seja, a imputação de sanções ao adolescente, aplicando-lhe medidas socioeducativas, só seria justificável se a proteção a bens jurídicos fundamentais não pudesse ser conferida por "meios menos gravosos".

A perspectiva de normatizar as condutas dos adolescentes reconhecidas como desviantes, a partir de um conceito material de ato infracional, da subsidiariedade da intervenção socioeducativa, coaduna com a necessidade de adequação da atuação do legislador a um viés de proporcionalidade ao definir "proteção a bens jurídicos fundamentais", que deve ser limitada à legitimidade dos meios e dos fins, bem assim buscar a adequação dos meios com vista aos fins pretendidos e a necessidade de utilização desses meios.

O modelo previsto no Estatuto da Criança e do Adolescente de normatização das condutas infracionais e de imputação das medidas socioeducativas/sanções, com consequente responsabilização do adolescente, precisa ser aprimorado, a fim de não violar os Direitos Humanos pela atuação do legislador.

Atualmente, o Estatuto da Criança e do Adolescente confere a condutas desviantes de pequeno potencial ofensivo possibilidade de aplicação de medidas socioeducativas restritivas de direitos que não são possíveis de serem aplicadas aos imputáveis; situação grave que viola o direito à proteção integral por conferir tratamento mais rigoroso aos adolescentes em conflito com a lei.

O aprimoramento na normatização das condutas desviantes perpassa a adoção de um conceito material de ato infracional que impõe a redução das condutas infracionais ao limitar os atos infracionais a condutas capazes de causar violação a bens jurídicos fundamentais, e no reconhecimento da subsidiariedade da intervenção socioeducativa que deve ser limitada à proteção de bens jurídicos diante da inexistência de meios mais eficazes. 
Conferir caráter material ao conceito de ato infracional e reconhecer a subsidiariedade da intervenção socioeducativa é densificar e dar concretude à proteção integral e às normativas internacionais das quais o Brasil é signatário, notadamente as Regras Mínimas de Beijing e as Diretrizes de Riad. A primeira, quando preconiza o bem-estar e o tratamento equitativo e humanitário ao adolescente e a redução da intervenção estatal; a segunda, ao apregoar a importância de políticas e medidas progressivas com a finalidade de evitar a criminalização e a penalização de condutas incapazes de prejudicar o desenvolvimento do adolescente e a ordem social.

Firmadas as bases para a normatização das condutas que podem ser reconhecidas como ato infracional, a partir do conceito material, e reconhecida a subsidiariedade da intervenção socioeducativa, a análise se volta, agora, para a forma de responsabilização dos adolescentes, sua legitimidade, adequação e necessidade.

\section{A RESPONSABILIZAÇÃO DO ADOLESCENTE}

A análise da intervenção estatal na esfera da responsabilização do adolescente pela prática de atos infracionais é perpassada por um juízo de proporcionalidade quanto à legitimidade, adequação e necessidade das medidas socioeducativas no processo de responsabilização e ressocialização do adolescente em conflito com a lei.

Reconhecido o sistema de responsabilização do adolescente como autêntico Direito Penal Juvenil, torna-se necessário estabelecer a compreensão e o enquadramento das medidas socioeducativas dentro da estrutura do Estatuto da Criança e do Adolescente.

O sistema de garantias ao adolescente estruturado no Estatuto da Criança e do Adolescente tem fundamento no princípio da prioridade absoluta (art. 227 da Constituição Federal, de 1988, e art. $4^{\circ}$ do Estatuto da Criança e do Adolescente, de 1990), que pauta as diretrizes do sistema primário de garantias e estabelece as diretrizes das políticas públicas com priorização das crianças e dos adolescentes, a partir da situação peculiar de pessoas em desenvolvimento (SARAIVA, 2004).

A estruturação dos sistemas de garantias no Estatuto da Criança e do Adolescente é feita em três grandes eixos: o primário, que representa as políticas sociais básicas com caráter universal; o secundário, que engloba as políticas de proteção especial, tendo como mote a condição fática da criança e do adolescente na situação de vitimização e de violação de direitos fundamentais, a partir do que se 
denominou situação de risco ${ }^{2}$, conforme art. 98 do Estatuto da Criança e do Adolescente; e o terceiro, das medidas socioeducativas direcionadas ao adolescente autor de ato infracional.

direito penal juvenil corresponde ao sistema terciário ou socioeducativo, e as medidas socioeducativas são postas como mecanismo de responsabilização do adolescente pela prática de ato infracional, com inegável viés sancionador.

Tonial (2004, p. 45) reconhece uma natureza jurídica complexa às medidas socioeducativas integrando ao caráter sancionador o pedagógico; e aponta três questões primordiais à legitimação, necessidade e adequação das medidas socioeducativas que são o decurso do tempo, a existência de intervenções socioeducativas em curso e a necessidade da socioeducação do adolescente.

Sendo as medidas socioeducativas de caráter híbrido a imputação da sanção, diante da prática do ato infracional, somente se "justifica quando estritamente necessária a uma atividade pedagógica”, ou seja, é dirigida finalisticamente a uma proposta pedagógica (TONIAL, 2004, p. 46).

A proporcionalidade da responsabilização do adolescente deve ser guiada pela legitimidade, necessidade e adequação da sanção aos seus fins pedagógicos. Ausentes os fins pedagógicos da sanção, a aplicação da medida socioeducativa, qualquer que seja, fica vazia de finalidade e não é admitida (art. 228 da Constituiçãa Federal), sob a pena de ferir os Direitos Humanos.

A desnaturação do caráter sancionatório ou pedagógico da medida socioeducativa conduz ao fenômeno da desvinculação. Desvinculação própria quando há a degradação do conteúdo pedagógico e remanesce apenas o caráter sancionador; e desvinculação imprópria, quando não subsiste o caráter sancionador e se mantém a intervenção pedagógica sob o argumento de ser "benéfica" ao adolescente. Em quaisquer dos casos, de desvinculação - própria ou imprópria -, não há de ser aplicada, e se foi, não deve ser executada (TONIAL, 2004).

A desvinculação própria ocorre em três situações: por erosão, consunção e substituição. Identificadas quaisquer das formas de vinculação, a medida socioeducativa, despida do caráter pedagógico, perde a justificação (TONIAL, 2004). A desvinculação por consunção tem lugar quando a aplicação de uma medida socioeducativa advém de outra mais abrangente e limitadora. Já a desvinculação por substituição decorre da responsabilização penal do jovem em cumprimento de medida socioeducativa. Nesse caso, a intervenção punitiva se sobrepõe à socioeducativa.

2 Art. 98. As medidas de proteção à criança e ao adolescente são aplicáveis sempre que os direitos reconhecidos nesta Lei forem ameaçados ou violados: I - por ação ou omissão da sociedade ou do Estado; II - por falta, omissão ou abuso dos pais ou responsável; III - em razão de sua conduta. 
As situações de desvinculação por consunção e por substituição foram reconhecidas, em certa medida, na Lei $n^{\circ} 12.594$, de 2012, que institui o Sinase (BRASIL, 20I2). A hipótese de substituição prevê a extinção da medida socioeducativa quando for aplicada pena privativa de liberdade, a ser cumprida em regime fechado ou semiaberto, em execução provisória ou definitiva (art. 46, inciso III); possibilitando, também, à autoridade judiciária reconhecer a extinção da execução da medida socioeducativa quando o jovem, em cumprimento da medida, estiver respondendo a processo-crime ( $\S 1^{\circ}$ do art. 46).

Pode-se identificar situação de desvinculação por consunção quando o legislador reconhece a absorção de atos infracionais, praticados pelo adolescente, anteriores à aplicação da medida socioeducativa de internação, e veda a imputação de nova medida ( $\$ 2^{\circ}$ do art. 44).

A desvinculação por erosão decorre do decurso do tempo entre a prática do ato infracional e o início da responsabilização do adolescente com a intervenção socioeducativa. O tempo talvez seja o principal fator a deslegitimar a responsabilização do adolescente por desnaturar o caráter finalístico pedagógico e remanescer apenas o sancionador. $O$ efeito do tempo é muito mais perceptível na adolescência, as transformações ocorrem com rapidez e nos força a constatação de que o tempo na adolescência é diferente do tempo no adulto.

A manutenção do caráter pedagógico da medida socioeducativa requer a imediaticidade da intervenção. A ausência de uma correlação temporal entre $O$ ato infracional e a imputação da medida socioeducativa não raro conduz à perda do caráter pedagógico, remanescendo apenas o sancionador, deslegitimando, dessa forma, a aplicação da medida por ser inadequada e desnecessária.

Dentre as possibilidades de extinção das medidas socioeducativas contempladas no Sinase (art. 46) há previsão de declaração da extinção por realização da sua finalidade (art. 46, inciso III). Com caráter finalístico complexo - sancionador e pedagógico -, se a medida socioeducativa não atender a ambos deve ser declarada extinta a pretensão socioeducativa e afastada a responsabilização do adolescente; mas se a medida socioeducativa for aplicada, fica impossibilitada a sua execução.

O reconhecimento da perda do caráter finalístico como causa de extinção da medida socioeducativa aplicada ou da pretensão socioeducativa decorre não apenas do decurso do tempo, mas também do reconhecimento que a socioeducação pode ocorrer na vida do adolescente sem a necessidade de intervenção estatal. Nessa linha,

[...] não devemos crer que apenas o sistema de garantias promova a socioeducação. Esta pode vir a ocorrer pela ação das instâncias informais, e talvez pela própria experiência de vida do adolescente. A socioeducação, repito, não é um privilégio ou uma exclusividade do Poder Judiciário. A socioeducação pode ocorrer na família, na escola, na comunidade, que inegavelmente também 
possui (ou deve possuir) seus mecanismos de reação à prática de certas condutas indesejáveis. Pensar de modo contrário é atribuir um valor desmesurado à ação estatal, é estabelecer uma presunção juris et de jure de imprescindibilidade da providência judicial, o que não é verdade. (TONIAL, 2004, p. 50).

O reconhecimento de que formas plurais podem interagir no processo de socioeducação do adolescente aloca a intervenção estatal no seu lugar natural, qual seja, de excepcionalidade e subsidiariedade do sistema de garantia socioeducativa na responsabilização do adolescente.

A natureza excepcional e subsidiária da intervenção estatal encontra fundamento e justificativa nas normativas internacionais - nas Regras de Beijing e nas Diretrizes de Riad - quando reconhece o papel da família, dos atores sociais e da escola no processo de socialização e integração; preconiza a redução da intervenção estatal ao limitar o processo judicial na socioeducação do jovem em conflito com a lei; insta a identificação de mecanismos minimizadores da aplicação da lei que possam tratar o adolescente de forma eficaz, equitativa e humanitária; reconhece a condição de sujeito ao adolescente com papel social ativo e colaborante; e rechaça a possibilidade de ser mero objeto de medidas de socialização e controle.

Pode-se concluir que a intervenção estatal, no tocante à responsabilização do adolescente em conflito com a lei, só preserva a proporcionalidade quando a medida socioeducativa for legítima, adequada e necessária. Legitimidade, adequação e necessidade umbilicalmente ligadas ao seu caráter finalístico: sancionatório e pedagógico. Sem a aderência do seu caráter sancionatório e pedagógico, a medida socioeducativa sobre o fenômeno da desvinculação deve ser extinta por não mais justificar a responsabilização diante da extinção da pretensão socioeducativa estatal.

\section{CONSIDERAÇÕES FINAIS}

O presente estudo parte do reconhecimento da existência de um direito penal juvenil para tentar delinear parâmetros de aplicação das teorias do direito penal mínimo e da subsidiariedade da intervenção punitiva no âmbito das condutas praticadas por adolescentes e tidas como desviantes (art. 108, ECA); e também analisar como se legitima a intervenção estatal na esfera da responsabilização do adolescente pela prática de atos infracionais.

Os critérios da análise foram delineados reconhecendo que a Constituição define proteção a bens jurídicos fundamentais e limita a atuação do legislador ao princípio da proporcionalidade, que requer a verificação se o amplo espectro dos atos infracionais confere proteção integral ao adolescente diante da infração, bem 
como se as medidas socioeducativas, como mecanismos retributivo e ressocializador são adequados e necessários para responsabilizar e ressocializar o adolescente.

Tendo como premissas básicas que amplo espectro de condutas normatizadas como desviantes - crimes e contravenções - e a desvinculação das medidas socioeducativas do seu caráter sancionatório e pedagógico não coadunam com o agir proporcional do legislador por não conferir proteção integral, foram analisados os instrumentos normativos que regulam a responsabilização penal juvenil, os princípios do direito penal mínimo, da subsidiariedade da intervenção punitiva, e, sob o enfoque da responsabilização dos adolescentes, os limites da intervenção estatal.

A análise permitiu demonstrar a necessidade de aprimorar o modelo previsto no Estatuto da Criança e do Adolescente de normatização das condutas infracionais e de imputação das medidas socioeducativas/sanções, com consequente responsabilização do adolescente, a fim de compatibilizar com as premissas traçadas nas normativas internacionais, com os paradigmas do estado democrático de direito e a condição de sujeito de direitos com prioridade absoluta.

O conceito material de crime e da subsidiariedade da intervenção penal, pelos processos de descriminalização e diversificação, permitiu vislumbrar a possibilidade de normatização das condutas desviantes. A aplicação analógica do conceito material de crime possibilitou delinear um conceito material de ato infracional para reconhecer o caráter infracional apenas às condutas que violem bens jurídicos fundamentais.

Já a subsidiariedade da intervenção socioeducativa, num processo de diversificação, possibilitou inferir a limitação à proteção de bens jurídicos, com um viés sancionador de imputação pessoal, somente quando não houver meios mais eficazes, conferindo à intervenção socioeducativa o caráter de ultimaratio.

Limitar os atos infracionais a condutas com potencialidade de violar bens jurídicos fundamentais e conferir a intervenção socioeducativa um caráter subsidiário, coaduna com a necessidade de adequação da atuação do legislador ao princípio da proporcionalidade. E, ao mesmo tempo, atende às diretrizes das normativas internacionais - Regras de Beijin e Diretrizes de Riad - quando limitam a intervenção estatal e a penalização e criminalização de condutas que não têm repercussão no desenvolvimento do adolescente e na ordem social.

A adequação dos meios, para a consecução dos objetivos pretendidos e a verificação da necessidade de sua utilização, é outro viés do princípio da proporcionalidade, que fixa os limites da intervenção estatal na esfera da responsabilização punitiva/socioeducativa.

O reconhecimento das medidas socioeducativas de caráter sancionador confere base e justificação para adoção do direito penal juvenil e permite analisar a intervenção estatal, na esfera da responsabilização do adolescente, quando da 
prática de atos infracionais por um juízo de proporcionalidade quanto à legitimidade, à adequação e à necessidade das medidas socioeducativas no processo de responsabilização e ressocialização do adolescente em conflito com a lei.

As medidas socioeducativas têm natureza jurídica complexa. Ao caráter sancionador agrega o pedagógico. A proporcionalidade da responsabilização do adolescente se densifica quando a legitimidade, a necessidade e a adequação da sanção aderem aos fins pedagógicos. Ausentes os fins pedagógicos, a aplicação da medida socioeducativa, qualquer que seja, fica vazia de finalidade e não é admitida (art. 228, CF). Fere os Direitos Humanos por desprezar o direito à proteção integral.

Pensando a necessidade de se identificarem mecanismos que possibilitem uma intervenção socioeducativa mínima, o presente artigo buscou trazer posições doutrinárias que possam subsidiar, a partir do direito penal juvenil, da teoria da proteção integral e das normativas internacionais, a concretização do viés excepcional e subsidiário da intervenção estatal na socioeducação do adolescente.

Pode-se concluir que o reconhecimento da legitimidade e adequação dos tipos que imputem uma conduta desviante ao adolescente deve resguardar direitos fundamentais; só se justificando a intervenção socioeducativa quando não for possível a responsabilização por outro meio; intervenção socioeducativa como ultimaratio. E, ainda, que os limites da intervenção estatal na responsabilização do adolescente em conflito com a lei deve ser proporcional. Proporcionalidade que requer legitimidade, adequação e necessidade da medida socioeducativa, aferidas a partir do seu caráter finalístico: sancionatório e pedagógico.

\section{REFERÊNCIAS}

BITENCOURT, Cézar R. Tratado de direito penal: parte geral I. I $5^{\mathrm{a}}$. ed. São Paulo: Saraiva, 2010.

BRASIL. Lei $n^{\circ}$. 8.069/90.13 de julho de 1990. Dispõe sobre o Estatuto da Criança e do Adolescente, e dá outras providências. Disponível em: http:// www.planalto.gov.br/ccivil_03/leis/L8069.htm Acesso em: 24 maio 2017.

. Decreto n. 99.710, de 21 de novembro de 1990. Promulga a Convenção sobre os Direitos da Criança. Disponível em: http://www.planalto.gov.br/ ccivil_03/decreto/I990-1994/d99710.htm Acesso em: 24 maio 2017.

. Decreto-Lei n. 3689, de 3 de outubro de 1941. Código de Processo Penal. Disponível em: http://www.planalto.gov.br/ccivil_03/decreto-lei/Del3689Compilado.htm Acesso em: 24 maio 2017. 
. Lei n. 6.697, de 10 de outubro de 1979. Institui o Código de Menores. Revogada pela Lei $n^{\circ} .8 .069$ de 13 de julho de 1990, Estatuto da Criança e do Adolescente. Disponível em http://www.planalto.gov.br/ccivil_03/leis/I9701979/L6697.htm. Acesso em: 24 maio 2017.

. Lei $n^{\circ}$. 12.594, de 18 de janeiro de 20 I2. Institui o Sistema Nacional de Atendimento Socioeducativo (SINASE), regulamenta a execução das medidas socioeducativas destinada a adolescentes que pratique ato infracional; e altera as Leis $n^{\circ}$. 8.069, de 13 de julho de 1990 (Estatuto da Criança e do Adolescente); 7.560, de 19 de dezembro de 1986, 7.998, de II de janeiro de 1990, 5.537, de 2 I de novembro de 1968, 8.3 I5, de 23 de dezembro de 199|, 8.706, de I4 de setembro de 1993, os Decretos-Leis n. 4.048, de 22 de janeiro de 1942, 8.621, de 10 de janeiro de 1946, e a Consolidação das Leis do Trabalho (CLT), aprovada pelo Decreto-Lei n ${ }^{\circ}$. 5.452 de maio de 1943. Disponível em http://www. planalto. gov.br/ccivil_03/_ato20 I I-20 I4/20 I2/lei// I2594.htm. Acesso em: 4 jun. 2017.

. Diretrizes das Nações Unidas para a prevenção da delinquência juvenil - Diretrizes de Riad. Disponível em http://www.dhnet.org.br/direitos/sip/ onu/c_a/lex45.htm. Acesso em: 24 maio 2017.

CARVALHO, Salo de; WEIGERT, Mariana de Assis B. As Alternativas às Penas e às Medidas Socioeducativas: estudo comparado entre distintos modelos de controle social punitivo. Sequência. n 64, p. 227-257. Florianópolis: UFSC, jul. 2012.

CAVALCANTI, Eduardo M. Crime e sociedade complexa. Campinas/SP: Ed. LZN, 2005.

MAIOR, Sotto O. Medidas socioeducativas. In: CURY, M. (Coord.). Estatuto da Criança e do Adolescente comentado: comentários jurídicos e sociais. $7^{\mathrm{a}}$. ed. São Paulo: Malheiros, 2004.

MENDES, Gilmar. Voto: Recurso Extraordinário n. 635.659/SP. Plenário STF. 20/08/20 I5. Disponível em: http://www.stf.jus.br/arquivo/cms/noticiaNoticiaStf/ anexo/RE635659.pdf Acesso em: 24/5/2017.

PRADO, Luiz R. Curso de direito penal brasileiro. volume 2. parte especial, arts. I2I a 183 / Luiz Regis Prado. 5a. ed. rev., atual. e ampl. São Paulo: Editora Revista dos Tribunais, 2006.

ROXIN, Claus. Estudos de direito penal. 2 ${ }^{\mathrm{a}}$ ed. Trad. Luís Greco. Rio de Janeiro: Renovar, 2008. 
SARAIVA, João Batista C. O adolescente em conflito com a lei e sua responsabilidade: nem abolicionismo penal, nem direito penal máximo. Revista Brasileira de Ciências Criminais: RBCCrim, v. I2, n.47, p. I23-145, mar./abr.2004.

TONIAL, Cleber A. Considerações pontuais sobre a aplicação das medidas socioeducativas. Tribunal de Justiça do Rio Grande do Sul, Corregedoria-Geral de Justiça. n I (Nov. 2003). Porto Alegre: Departamento de Artes e Gráficas do TJRS, 2003. 


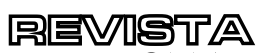
ESMAT

PAULO SÉRGIO GOMES SOARES / HÉLVIA TÚLIA SANDES PEDREIRA

$32 \begin{aligned} & \text { REVISTA ESMAT } \\ & \text { ANO 13 - No } 21 \\ & \text { Pás 13- 32 I JAN.ÄUN. } 2021\end{aligned}$ 